\title{
Mothers of Children with Hydrocephalus: Aspects about Prenatal Care
}

\author{
Debora Moura da Paixão Oliveira ${ }^{1, *}$, Carlos Umberto Pereira ${ }^{2}$, Zaira Moura da Paixão Freitas ${ }^{1}$ \\ ${ }^{1}$ Post-Graduate Nucleus of Medicine and Health, Federal University of Sergipe,. Aracaju, Sergipe, 49060-100, Brazil \\ ${ }^{2}$ Department of Medicine, Federal University of Sergipe, Aracaju, Sergipe, 49060-100, Brazil
}

\begin{abstract}
Hydrocephalus is a major cause of infant morbidity and mortality. Early diagnosis of hydrocephalus gives families more time to prepare to cope with their children's conditions. This study aimed to describe aspects about the prenatal care received in relation to time of pregnancy among mothers of children with hydrocephalus. The study was conducted with 54 mothers of children with congenital hydrocephalus in the Clinic of Neurosurgery at University Hospital in northeast Brazil. Fifty-one mothers received prenatal care (94.4\%); 44 (81.5\%) had not taken the folic acid. Four (7.8\%) mothers visited during the first month of pregnancy, forty (78.4\%) had their first visit after the fourth month of pregnancy. Despite their adherence to prenatal care, most of the mothers had their first visit after the fourth month of pregnancy. Strategies that encourage prenatal care as early as possible in the pregnancy should be implemented.
\end{abstract}

Keywords Hydrocephalus, Pregnancy, Prenatal

\section{Introduction}

Neural tube defects diseases (NTD) have decreased in recent years, as a result of more effective treatments, the development of diagnostic methods, surgical interventions and better nutrition and vitamin supplementation of pregnant women, however, the prevalence of NTD in Brazil puts the country at the level of countries with the highest rates of NTD in the world[1],[2].

Factors such as socio-economic and geographic area, regardless of ethnicity, are also associated with variations in the incidence of NTD. The most frequent association reported in the literature is the nutritional deficit of vitamins and minerals as folic acid and zinc during pregnancy[3],[4]. The supplementation with folic acid prior to becoming pregnant and during pregnancy reduces the risk of neural tube defects[5]. The supplemental use of folic acid in the first 28 days post conception reduces the risk of NTD; however, $50 \%$ of pregnancies are not programmed and are only discovered after the first month[6].

In Brazil is not permitted to terminate the pregnancy. Early prenatal care is important because the birth of a sick child presents numerous issues for the families, who need time to prepare themselves to meet their children's special needs[5]. The care of children with hydrocephalus requires among other things, learning to prevent complications and

* Corresponding author:

debora_aju@yahoo.com.br (Debora Moura da Paixão Oliveira)

Published online at http://journal.sapub.org/phr

Copyright (C) 2012 Scientific \& Academic Publishing. All Rights Reserved sequels, knowledge about the disease and high financial costs.

This study aimed to describe aspects about the socio-demographic dates and the prenatal care received in relation to time of pregnancy among mothers of children with hydrocephalus.

\section{The Prenatal Care}

The Brazilian Ministry of Health suggests a minimum number of six visits, with a maximum five-week interval between visits until 30 weeks, at which point the patient should be attended weekly until the 37 th week[7]

The prenatal consultations is conducted the physical examination, a gynecological / obstetric exam and counseling. Prenatal care consists of investigations by ultrasound examinations, blood count, blood glucose, ABO system, Rh factor, serology for rubella, toxoplasmosis, HIV/AIDS and supplementation with folic acid.

About $15 \%$ of Brazilian mothers had not only a medical consultation during pregnancy and about a third of them start prenatal care when no longer is possible to prevent a large number of diseases [5].

The literature mentions that the intake of folate is generally low even in developed countries [1], [2]. However pregnant women visited by community health agents began prenatal visits earlier than other groups, had more prenatal visits, lab tests, and clinical exams, and received more counseling on breastfeeding and iron supplementation[5].

\subsection{Hydrocephalus Diagnosis}


Exams as abdominal ultrasounds, abdominal magnetic resonance imaging and Doppler imaging of cranial arteries and fetal spine provided in routine prenatal care can facilitate the diagnosis of intrauterine fetal myelomeningocele or hydrocephalus[8],[9]. These tests can verify the presence of ventriculomegaly and other malformations when performed after 15 weeks of gestation[10],[11]. Despite, some authors believe that ultrasound examinations do not improve fetal prognosis[12],[13], the medical literature is unanimous in stating that the fetal ultrasound facilitates the diagnosis of hydrocephalus. This examination allows early diagnosis of fetal anomalies and has been used as a primary diagnostic method for screening congenital malformations[10],[11], [14],[15].

Approximately $52 \%$ of hydrocephalus cases are diagnosed during pregnancy, often via routine ultrasound examinations. It is of fundamental importance because it allows families to learn about potential complications of the disease[12],[16]. In addition to the ultrasound examination, prenatal diagnoses of hydrocephalus can be made using laboratory tests measuring the level of acetylcholinesterase, the amount of alpha-fetoprotein in maternal blood or amniotic fluid. Together, these assays can detect abnormalities in $85 \%$ to $90 \%$ of cases[16],[17]. This shows the prenatal care importance.

\section{The Study}

This is a descriptive, exploratory study with a quantitative approach. The study was conducted among 54 mothers of children with congenital hydrocephalus in the Clinic of Neurosurgery at University Hospital, Federal University of Sergipe in Aracaju. The mothers were recruited when at-tending consultations for children with hydrocephalus. We collected information on their experiences while pregnant with their hydrocephalic children.

Data collection was conducted from November 2007 to August 2008 using a questionnaire technique. We used a form with questions dealing with variables defined for the purpose of our research. Before initiating the study, the survey instrument was tested in a pilot study with ten mothers. No problems with the questions were noted. The results showed clear understanding. The survey took a median time of 40 minutes to complete. We collected socioeconomic data such as age, city of origin, education, family income, gesta-tional age at first consultation, number of consultations and exams. Prenatal care data were obtained from the parent and complemented with information contained in the child's medical records.

The project was approved by the Ethics Committee of the Federal University of Sergipe, with identification number 0126.0.107.000-07. The mothers agreed to participate in the study and signed a consent form, ensuring the ethical standards provided in Ordinance No. 196/96 of the National Ministry of Health.

Data were analyzed as frequencies and percentages using Statistical Package for Social Sciences (SPSS) version 16.0.

\section{Results}

The sample comprised 54 mothers aged 18 to 52 years (mean $27.3 \pm 7$ years). Thirty-eight mothers $(70.4 \%)$ were from the rural zone of Sergipe and the neighbouring states of Bahia and Alagoas.

With regard to schooling, 13 (24.1\%) had less than four years of study, 23 (42.6\%) had between four and eight years and $18(33.3 \%)$ had completed eleven years of study.

Regarding household income, 30 mothers $(55.6 \%)$ reported minimum income, $8(14.8 \%)$ had two times the minimum income and $16(29.6 \%)$ lived on less than minimum income. Overall, 51 mothers $(94.4 \%)$ received prenatal care: $16(31.4 \%)$ in the capital and $35(68.6 \%)$ in the interior. However, 44 (81.5\%), although making the prenatal, had not taken the folic acid (Figure 1).

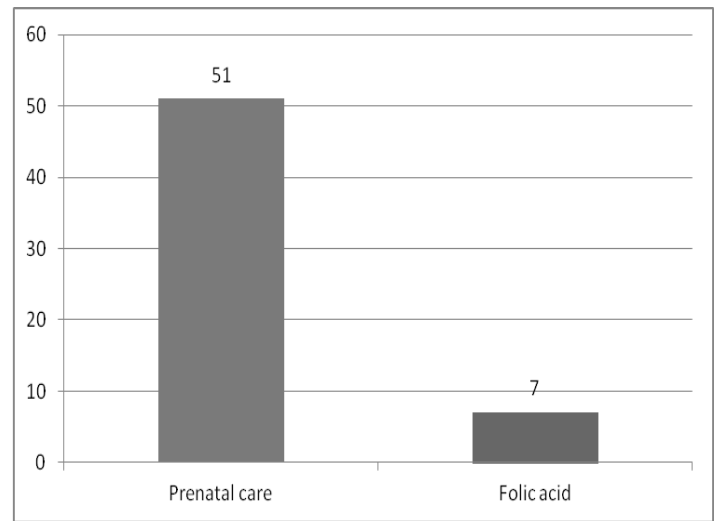

Figure 1. Comparation among prenatal care received and supplementation with folic acid

Among the mothers who had prenatal care, four (7.8\%) visited during the first month of pregnancy, seven (13.7\%) between the second and third month of pregnancy and forty (78.4\%) had their first visit after the fourth month of pregnancy (Figure 2).

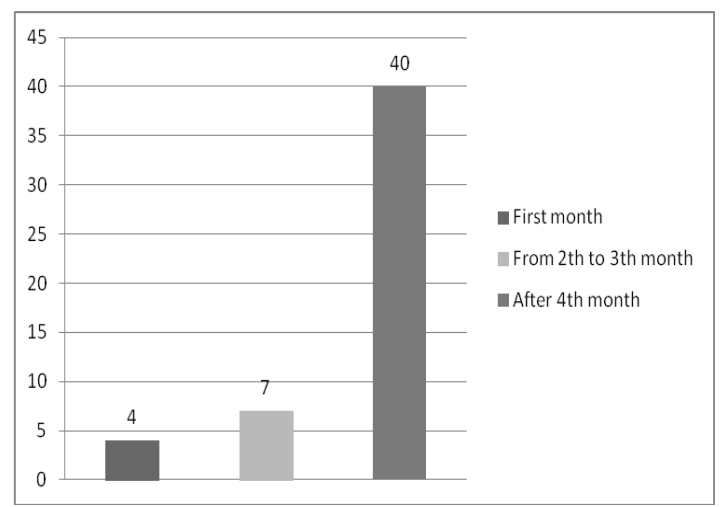

Figure 2. Gestational age for the first consultation

Regarding the number of consultations reported by the 51 mothers who received prenatal care, 2 (3.9\%) made only one visit to the clinic, $34(66.7 \%)$ made two visits, $14(27.5 \%)$ made three visits and $1(2 \%)$ made six visits (Figure 3 ).

Forty-seven mothers $(92 \%)$ underwent abdominal ultrasound. No mother underwent alpha-fetoprotein or acetylcholinesterase tests. 


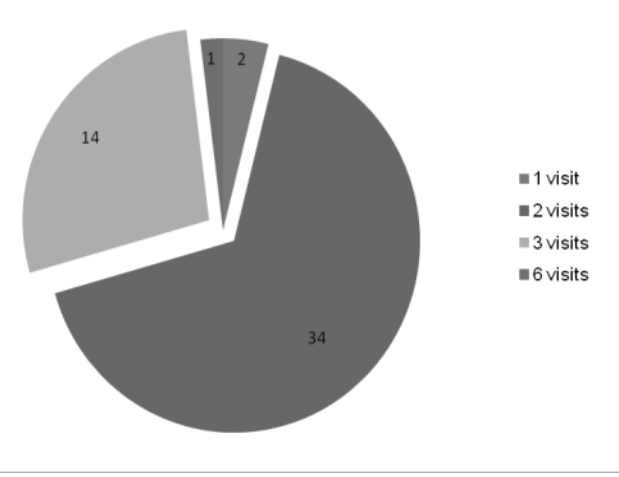

Figure 3. Number of consultations reported by the mothers who received prenatal care

\section{Discussion}

The birth of a sick child is often a sudden event for which the family is not prepared[18],[19]. Disease in a family member can be considered a crisis situation, depending on the severity and effect on quality of life[17]. Supported by literature on the importance of early prenatal diagnosis, our study aimed to investigate aspects of socio-demographic dates and the prenatal care received by the mothers of children with hydrocephalus. With respect to age, many of the mothers were relatively young. This finding corroborates other studies[6],[8] in the literature showing that prevalence of hydrocephalus is higher in children of young mothers.

With regard to schooling, we observed a good literacy rate among the women, though most mothers reported less than eight years of study. Other authors have also demonstrated a minimum standard of education in studies of this disease[20]. Brazilian studies showed that $46.1 \%$ of mothers of children with congenital malformations had only basic education and educational level ranged from 1 to 11 years of study[8],[21]. The low educational levels observed in this study might be related to the local research institution, which serves the lower social classes of the Brazilian Unified Health System.

With respect to place of origin, a previous study conducted among children with myelomeningocele found that $62 \%$ of the patients were from the rural zone and $15 \%$ were from other states[14]. These dates are similar to our survey.

Regarding family income, more than half of the sample reported a minimum wage-level income. Another study showed that the incidence of hydrocephalus is higher in families with lower income[20].

The survey showed that the mothers had good access to prenatal care, and ultrasounds. Pregnant women's access to prenatal care depends on the quality of care provided by both the clinic and the health professionals[7]. The good results obtained in this sample might be attributed to the Primary Care Program in place in this country.

Our findings related to access to prenatal care were consistent with those of other authors. A study reported in 1999 found that $85.1 \%$ had received one or more prenatal consultations[22]. However, despite the good clinical attendance of the women in this sample, the number of visits was still less than that recommended by the Brazilian Ministry of Health[7]. According to this agency, prenatal care should be initiated as early as possible, preferably before the end of the first quarter of pregnancy.

Studies have shown that prenatal ultrasound diagnosis of myelomeningocele can be made at an early gestational age[10],[11]. The diagnosis of hydrocephalus can be obtained in more than $98 \%$ of mothers by ultrasound, which is an easy, safe and low-cost exam[16]. Studies observed that the diagnosis of fetal malformation was established during the prenatal period in $85 \%$ of hydrocephalus cases[15]. Ninety six percent of the fetuses were correctly evaluated as having abnormal central nervous system findings on both fetal ultrasonography and fetal magnetic resonance imaging[9]. In $21.3 \%$ of cases of congenital malformation were diagnosed prenatally[8].

In our study many of the women had their first prenatal consultation after the fourth month of pregnancy, this fact suggests that health teams should enact strategies encouraging adherence to very early prenatal care[5].

An abnormal finding is always unexpected and can present quite a shock to parents during pregnancy. The two major dilemmas faced by families of children with congenital defects: the first is to doctors informing the parents that the problem exists; the second involves the uncertainty of disease progression during the course of pregnancy and after childbirth due to the complexity of the disease[12]. The diagnosis about the abnormality initially results in a shift in expectations and increased anxiety. Parents need clear information because the way the family reacts to the diagnosis and interacts with the affected children is crucial to their welfare[12],[23].

\section{Conclusions}

The findings of this study indicate that mothers of children with hydrocephalus come from the rural zone, present a low educational level and have a low economic status, which may have contributed to the low rate of early prenatal consultation.

Despite they received prenatal care, the number of visits was lower than that recommended by the Brazilian Ministry of Health. Most women had their first consultation after the fourth month of pregnancy.

This study draws attention to the need for strategies that encourage adherence to prenatal care and consultation. Early diagnosis of this condition facilitates understanding of the consequences of the disease and acceptance of the child as well as allows the mother to cooperate and guide their children to accept their possible limitations.

\section{REFERENCES}


[1] Santos LMP, Pereira MZ. Efeito da fortificação com ácido fólico na redução dos defeitos do tubo neural. Cad Saúde Pública, vol.23, no.1, pp.17-24, 2007.

[2] Wald NJ, Law MR, Morris JK, Wald DS. Quantifying the effect of folic acid. Lancet, vol.358, no. 9298, pp. 2069-2073, 2001.

[3] Birnbacher R, Messerschmidt AM, Pollak AP. Diagnosis and prevention of neural tube defects. Curr Opin Urol, vol.12, no.6, pp.461-464, 2002

[4] Mosley BS, Cleves MA, Siega-Riz AM, Shaw GM, Canfield MA, Waller DK et al. Neural tube defects and maternal folate intake among pregnancies conceived after folic acid fortification in the United States. Am J Epidemiol, vol.169, no.1, pp.9-17, 2009.

[5] Cesar JA, Mendoza-Sassi RA, Ulmi EF, Dall'Agnol MM, et al. Effects of different home visit strategies on prenatal care in Southern Brazil. Cad Saude Publica, vol.24, no.11, pp.2614-2622, 2008

[6] Bell KN, Oakley GP. Update on prevention of folic acid-preventable spina bifida and anencephaly. Birth Defects Research Part A: Clinical and Molecular Teratology, vol.85, no.1, pp.102-107, 2009. doi: 10.1002/bdra.20504.

[7] Ministry of Health. Assistência prenatal. In Manual Técnico. 3. ed. Secretaria de Políticas de Saúde: Brasília-Brasil, 2000.

[8] Guardiola A, Koltermann V, Aguiar PM, Grossi SP, et al. Neurological congenital malformations in a tertiary hospital in south Brazil. Arq Neuropsiquiatr, vol.67, no.3b, pp.807-811, 2009.

[9] Peruzzi P, Corbitt RJ, Raffel C. Magnetic resonance imaging versus ultrasonography for the in utero evaluation of central nervous system anomalies. J Neurosurg Pediatr, vol.6, no.4, pp.340-345, 2010.

[10] Nakamura-Pereira M, Cima LC, Llerena JC Jr, Guerra FA, et al. Sonographic findings in a case of tetrasomy $9 p$ associated with increased nuchal translucency and Dandy-Walker malformation. J Clin Ultrasound, vol.37, no.8, pp.471-474, 2009.

[11] Manganaro L, Savelli S, Francioso A, Di Maurizio M, et al. Role of fetal MRI in the diagnosis of cerebral ventriculomegaly assessed by ultrasonography. Radiol Med, vol.114, no.7, pp.1013-1023, 2009.

[12] Hortêncio APB, Landim ER, Nogueira MB, Feitosa FEL, et al. Avaliação ultra-sonográfica da hidrocefalia fetal: Associação com mortalidade perinatal. Rev Bras Gincecol Obstet, vol.23, no.6, pp.383-389, 2001.

[13] Cochrane DD, Kestle J. Ventricular shunting for hydrocephalus in children: patients, procedures, surgeons and institutions in English Canada, 1989-2001. Eur J Pediatr Surg, vol.12, no.1suppl, pp.6-11, 2002.

[14] Reece EA, Goldstein I. Early prenatal diagnosis of hydrocephalus. Am J Perinatol, vol.14, no.2, pp.69-73, 1997.

[15] Cavalcanti DP, Salomão MA. Incidência de hidrocefalia congênita e o papel do diagnóstico pré-natal. J Pediatr (Rio J), vol.79, no.2, pp.135-140, 2003.

[16] Chen CP. Prenatal diagnosis, fetal surgery, recurrence risk and differential diagnosis of neural tube defects. Taiwan $\mathrm{J}$ Obstet Gynecol, vol.47, no.3, pp.283-290, 2008.

[17] Fichter MA, Dornseifer U, Henke J, Schneider KTM, et al. Fetal spina bifida repair - Current trends and prospects of intrauterine neurosurgery. Fetal Diagn Ther, vol.23, no.4, pp.271-286, 2008.

[18] Gallo AM, Hadley EK, Angst DB, Knafl KA, et al. Parents' concerns about issues related to their children's genetic conditions. J Spec Pediatr Nurs, vol.13, no.1, pp.4-14, 2008.

[19] Barnoy S, Levy O, Bar-Tal Y. Nurse or physician: whose recommendation influences the decision to take genetic tests more? J Adv Nurs, vol.66, no.4, pp.806-813, 2010.

[20] Wohlfeiler MM, Macias MM, Saylor CF. Paternal correlates of cognitive and behavioral functioning in children with myelomeningocele. Dev Med Child Neurol, vol.50, no.11, pp.864-869, 2008 .

[21] Ulsenheimer MMM, Antoniuk SA, Santos LHC, Ceccatto MP, et al. Myelomeningocele. A Brazilian university hospital experience. Arq Neuropsiquiatr, vol.62, no.4, pp.963-968, 2004.

[22] Cáceres FM, Uscátegui AM, Rojas JD, Bacerra CH, et al. Registro durante um año de vigilância activa no selectiva em el Hospital Universitário Ramón Gonzalez Valencia. Medunab, vol.2, no.6, pp.109-114, 1999.

[23] Larsson AK, Svalenius EC, Lundqvist A, Dykes AK. Parents' experiences of an abnormal ultrasound examination vacillating between emotional confusion and sense of reality. Reprod Health, 7:10, 2010. http://www.reproductive-health-j ournal.com/content/7/1/10. 